Halaman 21-30

\title{
Study Komparasi Hasil Belajar Biologi dengan Penerapan Model Pembelajaran Inquiry Based Learning (IBL) dan Problem Based Learning (PBL) pada Siswa Kelas X SMA Negeri 5 Surakarta Tahun Pelajaran 2013/2014
}

\author{
A Comparative Study on Biology Learning Outcome by Applying \\ Inquiry Based Learning (IBL) and Problem Based Learning (PBL) Models in \\ The X Graders of SMA Negeri 5 Surakarta in the School Year Of 2013/2014 \\ Tyas Nyonita $^{a}$, Slamet Santosa ${ }^{b}$, Joko Ariyanto ${ }^{c}$ \\ ${ }^{a}$ Pendidikan Biologi FKIP UNS, Email: tyasnyonita@ymail.com \\ ${ }^{\mathrm{b}}$ Pendidikan Biologi FKIP UNS, Email: slametsantosa_bio@yahoo.co.id \\ ${ }^{\mathrm{c}}$ Pendidikan Biologi FKIP UNS, Email: jokoariyanto_bio@yahoo.co.id
}

Diterima 2 Juli 2014, disetujui 4 Agustus 2014

\begin{abstract}
This study aimed to find out the difference of Biology learning outcome in the applications of Inquiry Based Learning (IBL) and Problem Based Learning (PBL) models in the X graders of SMA Negeri 5 Surakarta in the school year of 2013/2014. This study was a quasi experimental research with posttest only with nonequivalent control group design. This study employed Inquiry Based Learning model in the experiment-1 group and Problem Based Learning in the experiment-2 group. The population of research was all of the X MIPA graders of SMA Negeri Surakarta in the school year of 2013/2014. The sampling technique used was cluster sampling one, so that the X MIPA 2 grade was obtained as experiment 1 and X MIPA 5 grade as experiment 2 groups. Techniques of collecting data used were multiple choice test, observation sheet, and school document. The hypothesis testing was conducted using t-test. From the result of research, it could be concluded that there was a difference of biology learning outcome in the applications of Inquiry Based Learning (IBL) and Problem Based Learning (PBL) models in the X graders of SMA Negeri 5 Surakarta in the school year of 2013/2014.
\end{abstract}

Key Words: Inquiry Based Learning model, Problem Based Learning model, biology learning outcome

\section{Pendahuluan}

\section{Pembelajaran Biologi adalah} pembelajaran yang membutuhkan adanya suatu proses dalam mencapai tujuan pembelajarannya. Pernyataan tersebut sejalan dengan Siregar \& Nara (2010), yang menyatakan bahwa pembelajaran merupakan interaksi antara peserta didik dengan pendidik dan sumber belajar secara terencana dan terkendali untuk mencapai tujuan yang telah dibuat sebelumnya dalam lingkungan pem- belajaran. Tujuan pembelajaran yang dimaksudkan adalah peningkatan kompetensi siswa. Kompetensi yang dimaksudkan bukan hanya kompetensi siswa dalam hal pengetahuan melainkan dalam hal sikap dan keterampilan siswa. Sehubungan dengan biologi sebagai bagian dari sains maka sikap dan keterampilan siswa yang diharapkan muncul adalah sikap dan keterampilan siswa dalam bidang sains.

$$
\text { Berdasarkan realita yang terjadi }
$$
di lapangan menunjukkan bahwa 
pembelajaran Biologi hanyalah mengarah pada produk atau hasil yang ditunjukkan siswa bukanlah proses yang dilakukan siswa untuk menyusun pengetahuannya sendiri. Pembelajaran yang hanya berorientasi kepada produk atau hasil biasanya cenderung bersifat teacher centre, dimana guru berperan besar dalam proses pembelajaran sedangkan siswa hanya sebagai penerima informasi. Cara yang salah dalam penyampaian informasi atau pengetahuan akan berakibat tidak baik terhadap kompetensi siswa yang tercermin dari hasil belajar siswa. Pernyataan terebut didukung oleh hasil penelitian PISA (Programme for International Student Assessment) yang dipublikasikan oleh OECD (Organization for Economic Cooperation and Development) yang menyatakan bahwa hasil belajar sains siswa Indonesia kelas X SMA yang berkisar pada usia 15 tahun menurut tahun 2012 menunjukkan bahwa Indonesia menduduki peringkat ke 64 dari 65 negara, dengan rata-rata skor 382. Berdasarkan pernyataan tersebut dapat diketahui bahwa hasil belajar sains siswa Indonesia masih rendah dari pada negaranegara lain.

Melihat realita yang terjadi di lapangan yang telah dipaparkan sebelumnya, maka perlu adanya suatu model pembelajaran yang sesuai agar terjadi interaksi antara pendidik dan peserta didik agar terjadi suatu proses pembentukkan konsep bukannya sekedar proses transfer informasi. Model pembelajaran Inquiry Based Learning (IBL) dan Problem Based Learning $(P B L)$ diharapkan dapat digunakan untuk mengatasi masalah siswa dalam memperoleh pengetahuannya. UNVER (2011), menyatakan bahwa Inquiry Based Learning (IBL) dan Problem Based Learning (PBL) selalu sukses digunakan lebih dari 30 tahun dan terus digunakan dalam berbagai disiplin ilmu dan tingkat pendidikan.

Model pembelajaran IBL adalah suatu pendekatan yang digunakan dan mengacu pada suatu cara untuk mempertanyakan, mencari pengetahuan (informasi), atau mempelajari suatu gejala. Pembelajaran dengan pendekatan IBL selalu mengusahakan agar siswa selalu aktif secara mental maupun fisik. Materi yang disajikan guru bukan begitu saja diberitahukan dan diterima oleh siswa, tetapi siswa diusahakan sedemikian rupa sehingga mereka memperoleh berbagai pengalaman dalam rangka menemukan sendiri konsepkonsep yang direncanakan oleh guru (Aryani, 2006).

Sasaran utama kegiatan belajar mengajar dengan menggunakan pendekatan IBL ini meliputi keterlibatan siswa secara maksimal dalam proses kegiatan 
belajar mengajar dan mengembangkan sikap percaya pada diri sendiri (selfbelief) pada diri siswa tentang apa yang ditemukan dalam proses inkuiri. Pembelajaran dengan pendekatan inkuiri dapat menggunakan berbagai macam metode. Metode yang dipilih hendaknya tetap mencerminkan ciriciri pembelajaran dengan pendekatan inkuiri. Beberapa metode pembelajaran yang dapat digunakan dengan pendekatan inkuiri, antara lain: tanya jawab, diskusi, demonstrasi, dan eksperimen (Glynn, et al., 2010).

Pembelajaran dengan pendekatan IBL ini menurut Roestiyah (2008) adalah dapat membentuk dan mengembangkan "self-concept" pada diri siswa, membantu dalam menggunakan ingatan dan transfer pada situasi proses belajar yang baru, mendorong siswa berpikir dan bekerja atas inisiatifnya sendiri, bersikap obyektif, jujur dan terbuka, mendorong siswa untuk berpikir intuitif dan merumuskan hipotesisnya sendiri memberi kepuasan yang bersifat intrinsik, situasi proses belajar menjadi merangsang, dapat mengembangkan bakat atau kecakapan individu, memberi kebebasan siswa untuk belajar sendiri, siswa dapat menghindari dari cara-cara belajar yang tradisional, dapat memberikan waktu pada siswa secukupnya sehingga mereka dapat mengasimilasi dan mengakomodasi informasi.

Arends (2007) menyatakan bahwa esensinya PBL menyuguhkan berbagai situasi bermasalah yang autentik dan bermakna kepada siswa, yang dapat berfungsi sebagai batu loncatan untuk investigasi dan penyelidikan. PBL dirancang untuk membantu siswa mengembangkan keterampilan berpikir dan keterampilan menyelesaikan masalah, mempelajari peran-peran orang dewasa dan menjadi pelajar yang mandiri. Model ini menyediakan sebuah alternatif yang menarik bagi guru yang menginginkan maju melebihi pendekatan-pendekatan yang lebih berpusat pada guru untuk menantang siswa dengan aspek pembelajaran aktif dari model tersebut.

Trianto (2007) menyatakan bahwa tujuan PBL yaitu membantu siswa mengembangkan keterampilan berpikir dan keterampilan mengatasi masalah, belajar peranan orang dewasa yang autentik dan menjadi pembelajar yang mandiri. Sejalan dengan pendapat tersebut, pemecahan masalah merupakan salah satu strategi pengajaran berbasis masalah dimana guru membantu siswa untuk belajar memecahkan melalui pengalaman-pengalaman pembelajaran hands-on. 


\section{Metode Penelitian}

Penelitian ini telah dilaksanakan di SMA Negeri 5 Surakarta kelas X semester 2 tahun pelajaran 2013/2014 yang beralamat di Jl. Letjen Sutoyo 18 Solo. Penelitian ini dikategorikan sebagai metode eksperimen semu (Quasi exsperimental research). Desain peneli-tian ini menggunakan Post-Test Only with Noneequivalent Group dimana setelah melakukan perlakuan pada kelompok eksperimental, dilakukan postest pada kelompok eksperimental, baik kelompok eksperimental 1 maupun kelompok eksperimental 2 (Creswell, 2010). Kelas pertama yang dipilih digunakan sebagai kelas eksperimen 1 yang diberi perlakuan pembelajaran Inquiry Based Learning $(I B L)$ sedangkan kelas kedua sebagai kelas eksperimen 2 yang diberi perlakuan pembelajaran Problem Based Learning (PBL).

Populasi dalam penelitian ini adalah seluruh siswa kelas X MIPA SMA Negeri 5 Surakarta semester 2 tahun pelajaran 2013/2014 sebanyak lima kelas. Pengambilan sampel menggunakan teknik Cluster Sampling yang menghasilkan sampel kelas X MIPA 5 sebagai kelas yang diberi perlakuan model pembeajaran Inquiry Based Learning dan kelas X MIPA 2 sebagai kelas yang diberi perlakuan model pembelajaran Problem Based Learning.

Variabel bebas dalam penelitian ini adalah model pembelajaran Inkuiri Based Learning dan Problem Based Learning. Variabel terikat dalam penelitian ini adalah hasil belajar siswa yang meliputi hasil belajar kognitif, psikomotorik dan afektif. Metode pengumpulan data dengan menggunakan metode tes dan non tes. Metode tes dilakukan dengan tes pilihan ganda sedangkan metode non tes dengan menggunakan metode observasi dan dokumentasi.

Tes uji coba instrumen penelitian dilakukan untuk mengetahui validitas produk moment, dan reliabilitas soal tes kognitif. Selain validasi produk moment, instrumen juga divalidasi konstruk oleh ahli.

Analisis data penelitian dengan menggunakan uji $t$. Sebelum analisis data, dilakukan uji normalitas menggunakan uji Liliefors dan uji homogenitas dengan uji Levene's yang dibantu program SPSS 16.

\section{Pembahasan}

Hasil uji hipotesis perbedaan hasil belajar kognitif dengan penerapan model pembelajaran Inquiry Based Learning dan Problem Based Learning siswa kelas 
X SMA Negeri 2 Surakarta disajikan pada Tabel 1.

Tabel 1. Hasil Uji-t Terhadap Hasil Belajar Biologi Ranah Kognitif

\begin{tabular}{|c|c|c|c|}
\hline \multicolumn{3}{|c|}{$\begin{array}{l}\text { t-test for Equality of } \\
\text { Means }\end{array}$} & Hasil \\
\hline $\mathbf{t}$ & $\begin{array}{c}\mathbf{T} \\
\text { tabel }\end{array}$ & $\begin{array}{l}\text { Sig. }(2- \\
\text { tailed })\end{array}$ & Keterangan \\
\hline 2.093 & .886 & .040 & Sig. $<\alpha=0,05$ \\
\hline
\end{tabular}

Tabel 1 menunjukkan bahwa Sig. $<\alpha=0,05$ dan t-hitung $>$ t-tabel, sehingga Ho ditolak dan $\mathrm{H}_{1}$ diterima. Jadi dari uji perbedaan yang dilakukan menggunakan uji-t dapat didiskripsikan bahwa ada perbedaan hasil belajar biologi ranah kognitif kelompok eksperimen 1 yang menggunakan model pembelajaran $I B L$ dan kelompok eksperimen 2 yang menggunakan model pembelajaran $P B L$.

Perbedaan hasil belajar ranah kognitif ini terjadi karena perbedaan sintak antara kedua model pembelajaran yang mengakibatkan pengalaman belajar siswa berbeda dan seberapa besar pemahaman siswa terhadap materi pembelajaran juga berbeda. Sugihartono, dkk (2007) menyatakan bahwa factor internal dan factor eksternal kehidupan siswa mempengaruhi hasil belajar siswa. Apabila pernyataan tersebut dikaitkan dalam hasil penelitian maka dapat dinyatakan faktor eksternal yang berupa kondisi saat pembelajaran dengan proses dan langkah pembelajaran yang berbeda menghasilkan hasil belajar yang berbeda pula.

Kelas eksperimen 1 memliki ketuntasan 28,13\% dan kelas eksperimen 2 memiliki ketuntasan 43,75\%, jika diamati kelas eksperimen 2 memiliki tingkat ketuntasan yang lebih tinggi dari pada kelas eksperimen 1 dengan rata-rata nilai kognitif 72,92. Hasil yang lebih baik pada kelas eksperimen 2 tersebut bisa terjadi karena pada model pembelajaran $P B L$ siswa diajak untuk menemukan permasalahan nyata yang ada di kehidupan sehari-hari dan menentukan bagaimana cara penyelesaiannya. Barrow's (2002) menyatakan bahwa permasalahan yang ada tidak hanya untuk dipahami dan dianalisis oleh siswa melainkan siswa juga harus menemukan cara bagaimana penyelesainnya. Karena siswa berusaha menemukan penyelesaian terhadap permaslahan yang ada secara mandiri maka siswa mampu untuk menyusun pemahaman dan konsepnya sendiri tanpa paksaan atau lebih banyak intuisi dari guru melainkan atas dasar rasa keingintahuan siswa. Keingintahuan siswa yang besar membuat siswa ingin belajar lebih banyak dan mendapatkan pengalaman belajar yang lebih banyak pula (Mansur, et al, 2012).

Pembelajaran $I B L$ juga mengarahkan siswa untuk membentukan self concept yang artinya siswa secara 
mandiri membentuk pengetahuannya sendiri melalui eksperimen, sehingga siswa mampu merangsang dan mengembangkan bakat atau kecakapan individunya (Bushe, 2013). Namun dalam penelitian ini diketahui kelas eksperimen yang menggunakan model pembelajaran Inquiry Based Learning memiliki rata-rata nilai kognitif yang lebih rendah dari pada kelas yang menggunakan model pembelajaran Problem Based Learning, fenomena tersebut bisa saja terjadi karena kesiapan mental siswa yang masih rendah dan tingkat adaptasi siswa terhadap model pembelajaran $I B L$ yang belum baik. Sanjaya (2006) menyatakan bahwa kesiapan mental pada siswa diperlukan karena pada pembalajaran siswa dituntut mandiri dalam menentukan cara untuk mendapatkan pengetahuannya dan dalam pembelajaran IBL juga membutuhkan waktu yang lama untuk mampu beradaptasi dari model pembelajaran yang lama.

Hasil uji hipotesis perbedaan hasil belajar Psikomotor dengan penerapan model pembelajaran Inquiry Based Learning dan Problem Based Learning siswa kelas X SMA Negeri 2 Surakarta disajikan pada Tabel 2.
Tabel 2. Hasil Uji-t Terhadap Hasil Belajar Biologi Ranah Psikomotor

\begin{tabular}{cccc}
\hline \multicolumn{3}{c}{$\begin{array}{c}\text { t-test for Equality of } \\
\text { Means }\end{array}$} & Hasil \\
\hline \multirow{2}{*}{$\mathbf{t}$} & $\mathbf{T}$ & $\begin{array}{c}\text { Sig. }(2- \\
\text { tailed })\end{array}$ & Keterangan \\
& tabel & Sig. $<\alpha=0,05$ \\
\hline 2.306 & .886 & .024 & Sig $\alpha=0$ \\
\hline
\end{tabular}

Tabel 2 menunjukkan bahwa Sig. $<\alpha=0,05$ dan t-hitung > t-tabel, sehingga Ho ditolak dan $\mathrm{H}_{1}$ diterima. Jadi dari uji yang dilakukan menggunakan uji-t dapat didiskripsikan bahwa ada perbedaan hasil belajar biologi ranah psikomotor kelompok eksperimen 1 yang menggunakan model pembelajaran IBL dan kelompok eksperimen 2 yang menggunakan model pembelajaran PBL.

Hasil belajar ranah psikomotor berkaitan dengan keterampilan atau kemampuan bertindak setelah siswa menerima pengalaman belajar. Hasil belajar psikomotor dapat diamati saat siswa melakukan kegiatan fisik dalam proses pembelajaran. Kegiatan fisik dalam pembelajaran yang dimaksudkan bisa berupa eksperimen pada materi pelajaran yang digunakan dalam penelitian ini yaitu materi ekosistem. Penilaian terhadap hasil belajar psikomotor dilakukan dengan observasi yang telah ditentukan secara jelas rubrik penilaiannya sehingga data yang diperoleh bersifat objektif.

Berdasarkan uji hipotesis diketahui bahwa ada perbedaan hasil 
belajar psikomotor antara kelas yang menggunakan model pembelajaran Inquiry Based Learning dengan kelas yang menggunaka model pembelajaran Problem Based Learning. Secara deskriptif rata-rata hasil belajar kognitif kelas eksperimen 1 lebih rendah dari pada kelas eksperimen 2 yaitu sebesar 69,72 dan 72,92. Hal ini bisa terjadi karena pada model pembelajaran Problem Based Learning lebih memberikan ruang kepada siswa untuk lebih aktif secara fisik. Menurut Sudarman (2007) pembelajaran PBL memiliki kelebihan dapat menimbulkan aktivitas ilmiah siswa melalui kerja kelompok.

Model pembelajaran Inquiry Based Learning dan model pembelajaran Problem Based Learning sama-sama menuntut siswa untuk belajar mandiri. Mandiri yang dimaksudkan adalah siswa tidak hanya mendapatkan informasi dari guru melainkan secara aktif dalam bentuk aktivitas ilmiah untuk mencari dan membangun konsepnya. Menurut Sykko, Lyngved, dan Peppin (2012) dalam model pembelajaran Inquiry siswa di dorong untuk mencari pengetahuan sendiri melalui eksperimen. Pernyataan tersebut seharusnya memberikan alas an kuat bahwa siswa seharusnya aktif secara fisik melakukan aktifitas ilmiah yang diamati sebagai hasil belajar psikomotor. Namun dalam hasil penelitian ini diketahui bahwa hasil belajar psikomotor antara kelas eksperimen 1 dan kelas eksperimen 2 lebih rendah kelas eksperimen 1. Kelas eksperimen 1 adalah kelas yang menggunakan model pembelajaran Inquiry Based Learning. Pernyataan tersebut terbentuk karena di dalam kelas eksperimen 1 masih banyak siswa yang bergantung pada pada teman sekelompoknya, sehingga hanya beberapa anak yang bekerja dan yang lainnya hanya menerima hasilnya. Selaian masih kurangnya kesadaran siswa dalam melaksanakan eksperimen, tingkat adaptasi siswa terhadap proses pembelajaran juga masih rendah sehingga masih banyak siswa yang bingung dalam melakukan eksperimen sehingga mereka memilih diam dan hanya menonton siswa lain yang lebih paham tentang langkah-langkah yang harus dilakukan. Hasil belajar tidak hanya dipengaruhi oleh model pembelajaran yang digunakan melainkan dipengaruhi pula oleh kondisi pelajar dan pengajar (Dimyati \& Mudjiono, 1999).

Tabel 3. Hasil Uji-t Terhadap Hasil Belajar Biologi Ranah Afektif

\begin{tabular}{cccc}
\multicolumn{3}{c}{ t-test for Equality of } & Hasil \\
\hline & $\mathrm{T}$ & $\begin{array}{l}\text { Sig. }(2- \\
\text { tailed })\end{array}$ & Keterangan \\
& $\mathrm{T}$ & tabel & tans \\
\hline 6.197 & .886 & .000 & Sig. $<\alpha=0,05$ \\
\hline
\end{tabular}

Tabel 3 menunjukkan bahwa Sig.

$<\alpha=0,05$ dan t-hitung > t-tabel, 
sehingga Ho ditolak dan $\mathrm{H}_{1}$ diterima. Jadi dari uji yang dilakukan menggunakan uji-t dapat didiskripsikan bahwa ada perbedaan hasil belajar biologi ranah afektif kelompok eksperimen 1 yang menggunakan model pembelajaran $I B L$ dan kelompok eksperimen 2 yang menggunakan model pembelajaran $P B L$.

Hasil belajar ranah afektif merupakan hasil belajar yang berkaitan dengan sikap yang ditunjukkan siswa saat pembelajaran. Menurut Sukanti (2011) ranah afektif dalam pembelajaran memiliki 4 karakteristik yang penting yaitu minat, sikap, konsep diri dan nilai. Indikator afektif dalam pembelajaran sains merupakan sikap ilmiah yang diharapkan muncul pada saat proses pembelajaran. Pembelajaran sains tidak hanya menghasilkan produk dan proses dalam proses pembelajarannya tapi juga sikap (Rustaman, 2005).

Ranah afektif atau sikap yang diukur dalam penelitian ini adalah berani, disiplin, bekerjasama dan menghargai pendapat oranglain. Pengukuran aspek afektif menggunakan lembar observasi dengan rubrik penilaian yang jelas. Berdasarkan uji hipotesis yang dilakukan diketahui bahwa $\mathrm{H}_{0}$ ditolak dan $\mathrm{H}_{1}$ diterima yang berarti ada perbedaan yang signifikan antara hasil belajar ranah afektif kelas eksperimen 1 yang menggunakan model $I B L$ dengan hasil belajar ranah afektif kelas eksperimen 2 yang menggunakan model $P B L$. Menurut Claxton (2007) dalam penerapan model pembelajaran $P B L$ dapat menimbulkan keinginan siswa untuk melakukan "Collaborative"sehingga muncul kerjasama siswa dalam menyelesaikan permasalahan. Sedangkan dalam model pembelajaran Inquiry dapat membentuk sifat "leadership" siswa (Edinyang, 2012). Dari pernyataan tersebut dapat diketahui bahwa masing-masing model pembelajaran mampu menonjolkan sikap ilmiah yang berbeda. Sejalan dengan Sudjana (2010) yang menyatakan bahwa hasil belajar sejalan dengan pengalaman belajar yang diperoleh oleh siswa. Penerapan model pembelajaran yang berbeda akan memberikan proses pembelajaran yang berbeda pula oleh karenanya pengalaman belajar siswa menjadi berbeda pula.

Nilai rata-rata afektif kelas yang menggunakan model pembelajaran Inquiry Based Learning lebih rendah dari pada kelas yang menggunakan model pembelajaran Problem Based Learning. Nilai rata-rata untuk kelas eksperimen 1 sebesar 62,92 sedangkan kelas eksperimen 2 sebesar 76,58. Menurut De Graff (2003) dalam proses pembelajaran berbasis masalah siswa mampu menunjukkan sikap ilmiah yang dimiliki 
melalui kegiatan percobaan. Salah satu kelebihan inkuiri selain siswa dituntut untuk berpikir tingkat tinggi, siswa juga dapat mengembangkan sikap ilmiah seperti jujur, bertanggung jawab dan berani (Sumiati, 2009). Dari pernyataan tersebut dapat diketahui bahwa kedua model pembelajaran sama-sama berpengaruh baik terhadap hasil belajar afektif siswa, namun dalam penelitian didapatkan bahwa kelas eksperimen yang menggunakan model pembelajaran $I B L$ memiliki rata-rata hasil belajar yang lebih rendah, karena hasil belajar tidak hanya dipengaruhi oleh model pembelajaran yang digunakan melainkan juga dipengaruhi oleh faktor yang muncul dari dalam diri siswa terhadap situasi pembelajaran yang diperolehnya.Uno (2007) menyatakan bahwa hasil belajar siswa dipengaruhi oleh factor intrinsic dan ekstrinsik, factor instrinsik merupakan factor yang ada dalam diri siswa.

Berdasarkan uraian diatas menunjukkan bahwa ada perbedaan antara pengguanaan model pembelajaran Inquiry Based Learning dengan penggunaan model pembelajaran Problem Based Learning pada hasil belajar biologi siswa. Deskripsi data menunjukkan bahwa hasil belajar biologi siswa lebih baik pada kelas eksperimen yang menggunakan model pembelajaran
Problem Based Learning. Hasil yang lebih baik pada model pembelajaran Problem Based Learning dikarenakan sintaknya yang lebih memberi ruang kepada siswa untuk belajar berdasarkan kemampuannya sendiri sehingga siswa mampu membentuk pemahamannya sendiri. Pemahaman atau konsep yang terbentuk oleh siswa sendiri akan bertahan lebih lama dari pada pengetahuan yang didapatkan dari proses transfer melalui guru dengan siswa secara lisan maupun tulisan. Keadaan siswa dan kesiapan siswa untuk beradaptasi dengan model pembelajaran yang diterapkan juga berpengaruh terhadap hasil belajar siswa. Kasus dalam penelitian ini siswa kelas eksperimen yang menggunakan model pembelajaran Inquiry Based Learning kurang bisa beradaptasi dengan baik sehingga masih banyak siswa yang memilih diam dari pada berpartisipasi dalam proses pembelajaran.

\section{Kesimpulan}

Berdasarkan hasil penelitian perbedaan penerapan model pembelajaran Inquiry Based Learning (IBL) dan Problem Based Learning (PBL) terhadap hasil belajar biologi kelas $\mathrm{X}$ SMA Negeri 5 Surakarta Tahun Pelajaran 2013/2014 dapat disimpulkan bahwa ada perbedaan hasil belajar biologi pada penerapan model pembelajaran Inquiry Based Learning 
dengan penerapan model pembelajaran Problem Based Learning pada siswa kelas X SMA Negeri 5 Surakarta Tahun Pelajaran 2013/2014.

\section{Daftar Pustaka}

Arends, R. I. (2007). Learning to Teach Belajar untuk Mengajar. Yogyakarta: Pustaka Belajar

Aryani, R.S. (2006). Upaya Meningkatkan Hasil Belajar Kimia Melalui Model Pembelajaran Dengan Pendekatan IBL (Inquiry-Based Learning) pada Kelas XI SMA 12 Semarang. $\quad$ Skripsi Tidak dipublikasikan. Semarang. UNES Press

Barrows, H. S. (2002). Is it Truly Possible to Have Such a Thing as dPBL? Journal of Distance Education. 23(1):119-122

Bushe, R. G. (2013). Apreciative Inquiry Model. Journal of (ed.) Encyclopedia of Management Theory. 1-5

Claxton, G. (2007). Expanding young people's capacity to learn. British Journal of Educational Studies. 55(2): 115-134

De Graff, E., and Annete, C. (2003). Characteristics of Problem-Based Learning. Int. J. Engng Ed. 19(5): 657-662

Dimyati dan Mudjiono. (1999). Belajar dan Pembelajaran. Jakarta: Rineka Cipta

Edinyang, S.D., and Ubi, I.E. (2012). Relative Effectiveness Of Inquiry And Expository Methods of Teaching Social Studies on Academic Performanceof Secondary Students in Akwa Ibom State, Nigeri. British Journal of Arts and Social Sciences. 8(1): 95-102

Glynn, S. M,. Brickman, P., Armstrong, N., and Taasoobshirazi, G. (2011). Science Motivation Questionnaire II:Validation With Science Majors and Nonscience Majors. Research in Science Teaching Journal. 48(10): 1159-1176

Mansur, D.I., Kayastha, S. R., Makaju, R., and Dongol, M. (2012). Problem Based Learning in Medical Education. Journal of Kathmandu Univ Med. 10(4): 78-82

Roestiyah, NK. (2008). Strategi Belajar Mengajar. Jakarta: PT. Rineka Cipta

Rustaman, N.Y.(2005).Strategi Belajar Mengajar Biologi. Malang: UM Press

Sanjaya, W. (2006). Strategi Pembelajaran Berorientasi Standart Proses Pendidikan. Jakarta:Kencana Prenada Media

Sudarman. (2007). Problem Based Learning : Suatu Model Pembelajaran untuk Mengembangkan dan Meningkatkan Kemampuan Memecahkan masalah. Jurnal Pendidikan Inovatif, 2 (2): 1-6

Sudjana, N. (2010). Penilaian Hasil Proses Belajar Mengajar. Bandung: PT. Remaja Rosda Karya

Sugihartono. (2007). Psikologi Pendidikan. Yogyakarta: UNY Pres

Sukanti. (2011). Penilaian Afektif Dalam Pembelajaran Akuntansi. Jurnal Pendidikan Akuntansi Indonesia. 9(1): 74-82

Sumiati. (2009). Metode Pembelajaran. Bandung: CV Wacana Prima

Sykko, S. A., Lyngved, R., and Peppin, B. (2012). Working with Mathematics and Science teachers on inquirybased learning (IBL) approaches: Teacher beliefs. Journal of Didactica Norge. $6(1): 1-8$

Trianto. (2007). Model-model Pembelajaran Inovatif Berorientasi Kontruktivistik. Jakarta: Prestasi Pustaka

Uno, H., dan Kuadrat, M. (2009). Mengelola Kecerdasan dalam Pembelajaran. Jakarta: Bumi Aksara.

Unver, A.O., and Arabaciouglu, S. (2011). Overviews on Inquiry Based and Problem Based Learning Methods. Jurnal Pendidikan IPA. Prof. Dr. Mugla University. 303-310 